Infusiostherapie 1991;18:1

\title{
Impressum, Vol. 18, No. 1, 1991
}

Band 18, Heft 1, Februar 1991

Infusionstherapie

Internationale Zeitschnft für Infusionstherapie, klinische Ernährung und Transfusionsmedizin

Herausgeber

S. Karger

Verlag für Medizi $\pi$ und Naturwissenschaften $\mathrm{GmbH}$,

Postfach 1724, D-8034 Germering

Presserechtlich verantwortlich: Walter Kunz, Gesellschafter

DAi

$\mathrm{O}$

Offizielles Organ

der Deutschen Arbeitsgemeinschaft

für künstliche Ernährung (DAKE)

$<$ IПIAKE

$\mathrm{m}^{\wedge \wedge} \mathrm{Y}$ für klinische

Offizielles Organ

der Österreichischen Arbeitsgemeinschaft

für klinische Ernährung (AKE)

Offizielles Organ der Deutschen Gesellschaft für Transfusionsmedizin und Immunhämatologie

Griindungsherausgeber

H. Reissigl, w. Hofrat, Innsbruck

Schriftleitung

A. Grünert, Ulm V. Kretschmer, Marburg K. Widhalm, Wien G. Wolfram, München

Wissenschaftlicher Beirat

M. Adolph, Augsburg

F.W. Ahnefeld, Ulm

K.H. Bäßler, Mainz

W. Behrendt, Aachen

H. Bergmann, Linz

C. Bode, Köln

P. Deetjen, Innsbruck

W. Dick, Mainz

R. Dölp, Fulda

H. von Domarus, Lübeck

W. Druml, Wien

J. Eckart, Augsburg

P. Ferenci, Wien

H. Förster, Frankfurt

R. Glaser von Roman, Düsseldorf 
A. Grünert, Ulm

J.M. Hackl, Innsbruck

W. Haider, Wien

M. Halmágyi, Mainz W. Hartig, Leipzig O. Heidenreich, Aachen U. Henneberg, Berlin

E. Holm, Mannheim

G. Kleinberger, Steyr

K.F. Kopp, München

V. Kretschmer, Marburg

J. Kult, Bad Mergentheim

H. G. Lasch, Gießen

H. Lochs, Wien D. Löhlein, Dortmund H. Mehnert, München J.M. Müller, Köln K. Peter, München

F. Pohlandt, Ulm

U. Rabast, Hattingen H. Reissigl, Innsbruck

P. Riederer, Würzburg H. Rossegger, Graz

E. Roth, Wien

P. Schauder, Göttingen

H.P. Schuster, Hildesheim

M. Semsroth, Wien

K. Steinbereithner, Wien

H. J. Steinhardt, Mainz

H. Stoeckel, Bonn

B. Szczygiel, Warschau

W. Vahlensieck, Bonn

R. Weiner, Leipzig

R. Wenger, Wien

K. Widhalm, Wien

F. Willig, Heidelberg

G. Wolfram, München

R. Zander, Mainz

Erscheinungsweise

Die Zeitschrift erscheint zweimonatlich; pro Jahr erscheint 1 Band zu je 6

Heften.

Abonnementpreis

Bezugspreis für Jahrgang 18, 1991, DM 148,- I öS 1036,-/SFr 116,-.

1 Einzelheft kostet DM 28,-/öS 196,-/SFr 22,-, einschließlich MwSt., zuzüglich Postgebühren.

Der Abonnementpreis ist im voraus zahlbar. Das Abonnement der Zeitschrift läuft weiter, wenn es nicht spätestens 4 Wochen vor Abschluß eines Bandes abbestellt wird.

Abonnementbestellungen können bei jeder Buchhandlung oder direkt beim Verlag aufgegeben werden:

Bundesrepublik Deutschland/Österreích: S. Karger GmbH, Postfach 1724, D-8034

Germering/München, Telefon: (089) 843035, Telex: 524865 D, Telefax: 8418083, Postgiro:

München 40080-807 
Schweiz: S. Karger AG, Allschwilerstr. 10, Postfach, CH-4009 Basel, Tel.: (061) 3061111, Telex 62652 CH, Telefax (061) 3061234.

Manuskripte

Diese sind direkt an den Verlag zu senden; wegen Einzelheiten siehe unter

«Hinweise für Autoren» in diesem Heft.

Anzeigen

S. Karger Verlag für Medizin und Naturwissenschaften GmbH, Postfach 1724, D-8034

Germering, Telefon (089)843035. Gültig ist die Preisliste Nr. 9 vom 1.10.1990.

Für den Inhalt außerhalb des redaktionellen Teiles (insbesondere Anzeigen,

Industrieinformationen, Pressezitate und Kongreßinformationen usw.) überneh-men

Schriftleitung, Beirat und Verlag keine Gewähr.

Eine Markenbezeichnung kann warenzeichenrechtlich geschützt sein, auch wenn bei Ihrer

Verwendung in dieser Zeitschrift das Zeichen ${ }^{\circledR}$ oder ein anderer Hinweis auf etwa bestehende

Schutzrechte fehlen sollte. Für Satzfehler, insbesondere bei Dosierungsangaben, wird keine

Gewähr übernommen.

Alle Rechte, insbesondere das Recht der Vervielfältigung und Mikrokopie sowie der Übersetzung, vorbehalten. Nachdruck, auch auszugsweise, nur mit Geneh-migung des Verlages.

Fotokopien dürfen nur für den persönlichen Gebrauch als Einzelkopien hergestellt werden. Jede im Bereich eines gewerblichen Unterneh-mens zulässig hergestellte oder benutzte Kopie dient gewerblichen Zwecken gem. § 54(2) UrhG und verpflichtet zur Gebührenzahlung an die Verwertungs-gesellschaft WORT, Abt. VG Wissenschaft, Goethestr. 49, D-8000 München 2. (C) Copyright 1991 by S. Karger, Verlag für Medizin und Naturwissenschaften GmbH, Postfach 1724. D-8034 Germering (BRD)

Verlagsleitung: Manfred Just Redaktionsassistenz: Anna Schieber Anzeigenverkauf: Marlene Scholz Anzeígenverwaltung: Eva Lindenau Herstellung: Horst H. Bruch Vertrieb: Gabriela Taube

Satz und Druck: Walter Biering GmbH, Grafisscher Betrieb Freisinger Landstraße 21, D-8000

München 45 (BRD)

KARGER 